\title{
Energy Performance Optimization for an Office Building located in Guayaquil-Ecuador.
}

\author{
H. Sánchez ${ }^{l}$, G. Soriano ${ }^{l}$, J. Erazo ${ }^{l}$ and J. Urquizo ${ }^{l}$ \\ ${ }^{1}$ Escuela Superior Politécnica del Litoral, Ecuador, hegasanc@espol.edu.ec, gsorian@espol.edu.ec, jlerazo@espol.edu.ec, \\ jaurquiz@espol.edu.ec
}

\begin{abstract}
This study analyses the energy situation of the building "Government Zone of Guayaquil", and on this basis assesses the potential of energy efficiency criteria to reduce its electric consumption. As a first phase, it is necessary to gather historical data about energy consumption, weather conditions, building plans, characteristics of the building envelope, installed systems, lighting and other heat loads of the air conditioning system. These data are used to develop an energy simulation of the building, which is calibrated using the electric monthly consumption bills and the ASHRAE guideline 14-2002. The results obtained by the simulation of the calibrated model become the energy baseline for this study. Once the baseline is established, the simulation results are evaluated to identify the energy reduction opportunities in the building focusing on the mechanical system of the building. The measures proposed are two: One is to reduce the lift (head pressure) of the chillers, and the other is to implement variable frequency drives on mechanical components of the chilled water plant. Once the energy saving measures are defined; simulations are conducted to evaluate their effects. Improvements in building efficiency are assessed by a comparative analysis of the baseline model and the models of the proposed saving measures. The results indicate that it is possible to reduce up to $26.42 \%$ energy consumption when a chiller with a variable frequency drive is used along an adjustment of its outlet temperature. This study serves to illustrate the potential of energy use improvements in the operation of office buildings in Latin America.

Keywords-Energy efficiency, computer model, calibrated model, simulation, energy baseline, variable frequency drive, HVAC.
\end{abstract}

Digital Object Identifier (DOI):

http://dx.doi.org/10.18687/LACCEI2016.1.1.037

ISBN: 978-0-9822896-9-3

ISSN: 2414-6390

$14^{\text {th }}$ LACCEI International Multi-Conference for Engineering, Education, and Technology: "Engineering Innovations for Global Sustainability", 20-22 July 2016, San José, Costa Rica. 


\title{
Energy Performance Optimization for an Office Building located in Guayaquil-Ecuador.
}

\author{
H. Sánchez ${ }^{1}$, G. Soriano ${ }^{1}$, J. Erazo ${ }^{1}$ and J. Urquizo ${ }^{1}$ \\ 1Escuela Superior Politécnica del Litoral, Ecuador, hegasanc@espol.edu.ec, gsorian@espol.edu.ec, jlerazo@espol.edu.ec, \\ jaurquiz@espol.edu.ec
}

\begin{abstract}
This study analyzes the energy situation of the building "Government Zone of Guayaquil", and on this basis assesses the potential of energy efficiency criteria to reduce its electric consumption. As a first phase, it is necessary to gather historical data about energy consumption, weather conditions, building plans, characteristics of the building envelope, installed systems, lighting and other heat loads of the air conditioning system. These data are used to develop an energy simulation of the building, which is calibrated using the electric monthly consumption bills and the ASHRAE guideline 14-2002. The results obtained by the simulation of the calibrated model become the energy baseline for this study. Once the baseline is established, the simulation results are evaluated to identify the energy reduction opportunities in the building focusing on the mechanical system of the building. The measures proposed are two: One is to reduce the lift (head pressure) of the chillers, and the other is to implement variable frequency drives on mechanical components of the chilled water plant. Once the energy saving measures are defined; simulations are conducted to evaluate their effects. Improvements in building efficiency are assessed by a comparative analysis of the baseline model and the models of the proposed saving measures. The results indicate that it is possible to reduce up to $26.42 \%$ energy consumption when a chiller with a variable frequency drive is used along an adjustment of its outlet temperature. This study serves to illustrate the potential of energy use improvements in the operation of office buildings in Latin America.

Keywords-Energy efficiency, computer model, calibrated model, simulation, energy baseline, variable frequency drive, $\mathrm{HVAC}$.
\end{abstract}

\section{INTRODUCTION}

The building of the Government zone of Guayaquil was design and built in the nineties for the headquarters of "Banco del Progreso"; later it passed into the hands of the Ecuadorian state as a result of the financial crisis of 1999. The building remained closed about eight years until it was restored to function as a public building for government offices in 2007 .

This study seeks to evaluate opportunities for improved energy efficiency of the building, by simulating alternatives for reducing energy consumption, focusing on the HVAC system.

\section{A. Motivation of the study}

In the Ecuadorian coast, the climate is mainly influenced by ocean currents: the cold Humboldt Current and the warm current of "El Niño", resulting in a tropical climate [1]. Guayaquil, geographically located with latitude $2^{\circ} 16^{\prime}$ South and longitude $79^{\circ} 54^{\prime}$ West [2], has two seasons: "dry tropical" and "tropical monsoon" [3].

During the period comprising the months from December to May, a rainy season occurs on the Ecuadorian coast. In cities like Guayaquil, the values of temperature and humidity reach levels well above annual mean values. This increase in temperature and humidity cause greater demand for refrigeration and air conditioning systems, resulting in a rise in power demand. Figure 1 shows values of temperature and relative humidity for the year 2013 [3].

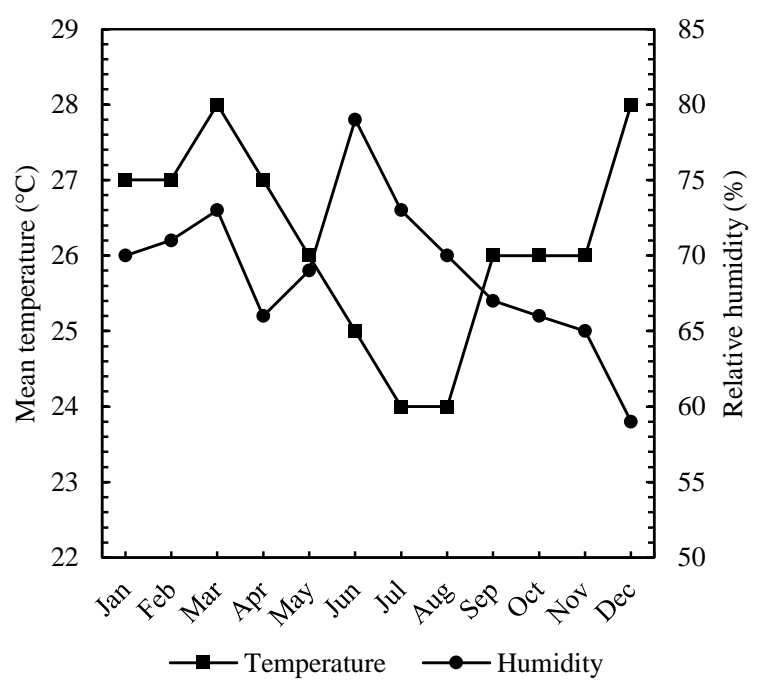

Fig. 1 Mean values of temperature and relative humidity in Guayaquil.

These figures show the need and importance of air conditioning systems in Guayaquil to achieve comfortable indoor conditions and optimal productivity of the same [4]. Therefore, it is crucial that buildings have efficient HVAC systems; and to quantify potential energy savings that are significant.

\section{B. Background and justification}

The efficient use of energy has been considered in developed countries for more than three decades as an additional energy source [5]. The initiatives by the Ecuadorian government to develop this area are relatively recent [6]. So for now, there are no current national regulations to cover the

Digital Object Identifier (DOI): http://dx.doi.org/10.18687/LACCEI2016.1.1.037 ISBN: 978-0-9822896-9-3

ISSN: $2414-6390$

14 ${ }^{\text {th }}$ LACCEI International Multi-Conference for Engineering, Education, and Technology: "Engineering Innovations for Global Sustainability”, 20-22 July 2016, San José, Costa Rica. 
complete requirements of energy efficiency in buildings. An alternative adopted is the use of international standards, being the ASHRAE standards, the most widely used [7,8].

Public policy and programs in energy efficiency require knowledge of local features such as climate, materials, and construction techniques, among others to be successful.

In Ecuador, in the field of energy efficiency in buildings Alvear et al. [9] showed a planning framework for zero-energy buildings, applied in the design of a prototype building in Ecuador. Regarding the impact of the envelope on the energy performance of Ecuadorian constructions, Macias et al. [10], presented a study of the effects of solar reflectance of roofing assemblies on energy behavior of social interest dwellings located in Guayaquil. In the particular case of this building, Naranjo et al. [11] conducted a comparative analysis and a projection of three different solar cooling system configurations for the 15 th floor of the building.

\section{Building Description}

The building has an architecture combining colonial and contemporary styles, the facade of the first three floors is composed of glass and concrete while the rest of the building has an entirely translucent facade. The proportion of glazed envelope is approximately $75 \%$.

The building has a basement with the parking, a ground floor with a large lobby area and 15 floors with approximately $20,635 \mathrm{~m}^{2}$ of net area. The building has a capacity of 1300 office workers, 250 telephone lines, seven elevators and a heliport that can support up to $2500 \mathrm{~kg}$.

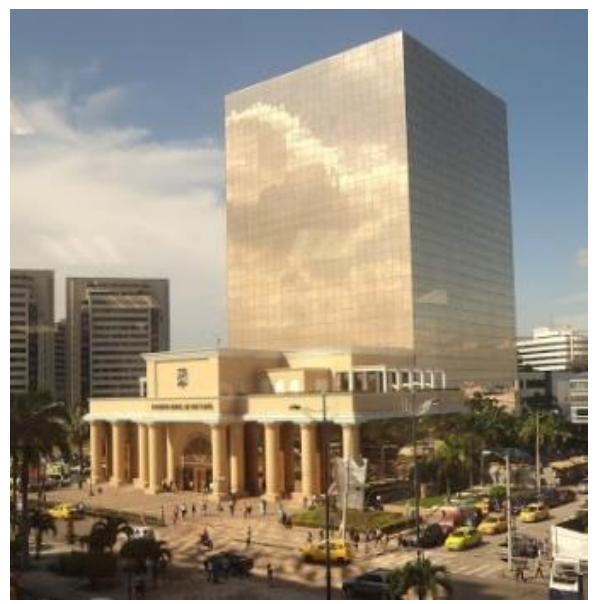

Fig. 2 Building of Government Zone of Guayaquil.
TABLE I

DIRECT EXPANSION EQUIPMENT CONSIDERED

\begin{tabular}{|c|c|c|c|}
\hline \multirow{2}{*}{ Floor } & Quantity & $\begin{array}{c}\text { Capacity } \\
{[\text { BTU/hour }]}\end{array}$ & Use \\
\hline 10 & 2 & 30,000 & Multiple \\
\hline 8 & 2 & 120,000 & Data center \\
\hline \multirow{2}{*}{4} & 1 & 60,000 & Auditorium \\
\cline { 2 - 4 } & 1 & 60,000 & \begin{tabular}{c} 
Auditorium's Hall \\
\hline 3
\end{tabular} \\
\cline { 2 - 4 } & 1 & 60,000 & $\begin{array}{c}\text { Lecture room and } \\
\text { Library }\end{array}$ \\
\hline \multirow{2}{*}{ PB } & 2 & 30,000 & $\begin{array}{c}\text { Communication's } \\
\text { room }\end{array}$ \\
\cline { 2 - 4 } & 2 & 60,000 & Cabins for attention \\
\hline
\end{tabular}

For climatization purposes, the building has a chiller plant; it also has some direct expansion equipment at particular points of the building. In the original design, the air conditioning and ventilation were handled by an intelligent control system, but now the system is disabled and checks are done manually. Most of the air conditioning is performed by the chilled water system which is comprised by chillers, cooling towers, air handlers, and a variable air volume (VAV) distribution system.

The operating temperature is between $21^{\circ} \mathrm{C}$ and $23{ }^{\circ} \mathrm{C}$, and an average relative humidity of $50 \%$. The chilled water system has three chillers, two of which are operating and are described below: One centrifugal chiller, with a capacity of 450 TON-R and one centrifugal chiller with a capacity of 500 TON-R. For the heat rejection of the system, there are two cooling towers and four pumps $(30 \mathrm{HP})$ for circulating water to the cooling towers.

For the air distribution of the building, there are four pumps (50 HP) for recirculation of cold water. On each floor there are two air handlers with a capacity of 180,000 BTU/Hour each, except on the 15th floor, which has three lower capacity air handlers: two handlers are 36,000 BTU/Hour, and one is 72,000 BTU/Hour also. Additionally, there is a stand alone 350,000 BTU/Hour unit for the exclusive use of the dining room. For the main lobby area, the system has two air handlers 380,000 BTU/Hour, for spectators in the auditorium of the building, has two 140,000 BTU/Hour equipment.

The centralized air conditioning system is complemented by direct expansion equipment located in certain areas of special requirements, Table I summarizes the number and capacity of direct expansion equipment situated on each floor and will be considered in the model.

\section{METHODOLOGY}

\section{A. Methodology workflow}

The study is divided into two periods: a baseline period and retrofit period, as shown in Fig. 3. The first one determines the energy baseline; while the other one focuses on determining the effect of the proposed measures on the energy performance of the building. 


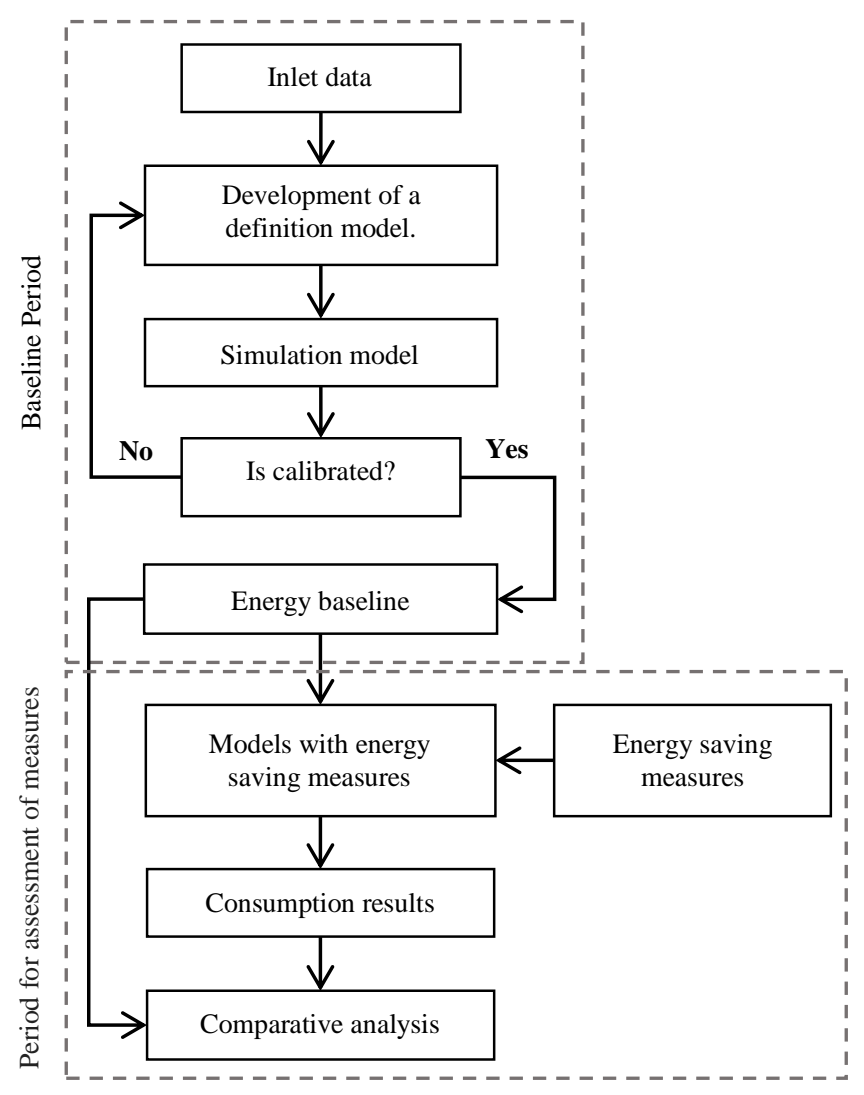

Fig. 3 Methodology diagram.

\section{B. Baseline Modeling}

A baseline model represents the use of the existing energy and operating conditions of the building. This model is to be used as a reference to estimate the energy savings incurred from appropriately selected energy conservation measures [12].

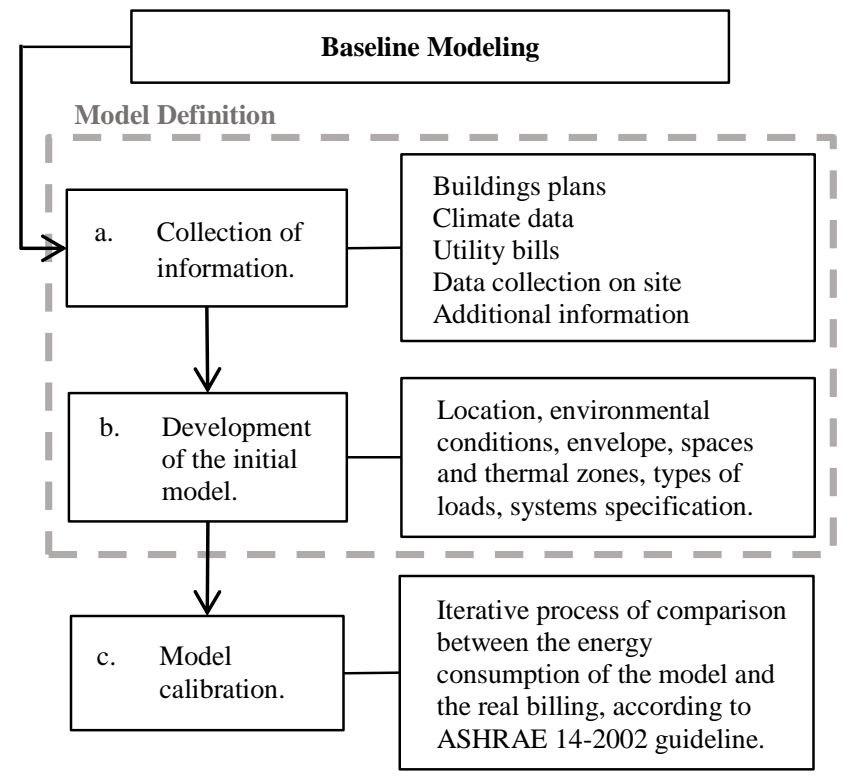

Fig. 4 Baseline modeling process.
Because the edification is already built, a modeling approach based on data is used [13]. This process means that, using the current building conditions, a baseline model that must be validated is developed.

Figure 4 shows the steps and information required for the baseline modeling, the first two stages have as objective to define the computer model; while the last involves the calibration process. The software used to generate the simulation file is Open Studio [14]; which it is an interface that facilitates interaction with Energy Plus that is the energy simulation engine [15].

To choose the calibration method to validate the model is necessary to consider the timeline with which actual building consumption is registered; then the calibration may be performed using, for example; a monthly method or an hourly method among others.

To validate the developed model is used as a reference the ASHRAE Guideline 14; in which the recommended statistical indices for calibration models are defined, expressions are shown below:

1) Coefficient of variation of the standard deviation (CVSTD):

$$
C V S T D=\frac{100}{\bar{y}} \times \sqrt{\frac{\sum\left(y_{i}-\bar{y}\right)^{2}}{n-1}}
$$

2) Coefficient of variation of the root mean square error (CVRMSE):

$$
\text { CVRMSE }=\frac{100}{\bar{y}} \times \sqrt{\frac{\sum\left(y_{i}-\hat{y}_{i}\right)^{2}}{n-p}}
$$

3) Normalized mean bias error (NMBE):

$$
N M B E=\frac{\sum\left(y_{i}-\hat{y}_{i}\right)}{\bar{y} \times(n-p)} \times 100
$$

Where $y$ is the dependent variable of some function of the independent variables, $\hat{y}$ is the regression model's predicted value of $y, \bar{y}$ is the arithmetic mean of the $n$ values of $y, n$ is the number of data points or periods in the baseline period and $p$ is the number of parameters or terms in the baseline model, as developed by a mathematical analysis of the baseline data [16]. Table II presents the acceptable ranges for each index (tolerances) according to the calibration method to be used.

TABLE II

TOLERANCES FOR CALIBRATION INDICES

\begin{tabular}{|c|c|c|}
\hline Calibration type & Index & Tolerance [\%] \\
\hline \multirow{2}{*}{ Monthly } & CVRMSE & \pm 5 \\
\cline { 2 - 3 } & NMBE & \pm 15 \\
\hline \multirow{2}{*}{ Hourly } & CVRMSE & \pm 10 \\
\cline { 2 - 3 } & NMBE & \pm 30 \\
\hline
\end{tabular}

$14^{\text {th }}$ LACCEI International Multi-Conference for Engineering, Education, and Technology: "Engineering Innovations for 


\section{Simulation of energy efficiency measures}

The retrofit phase of this study consists of the proposition and simulation of some energy saving measures, aimed at reducing energy consumption in HVAC systems. Figure 5 shows the steps to follow during this stage.

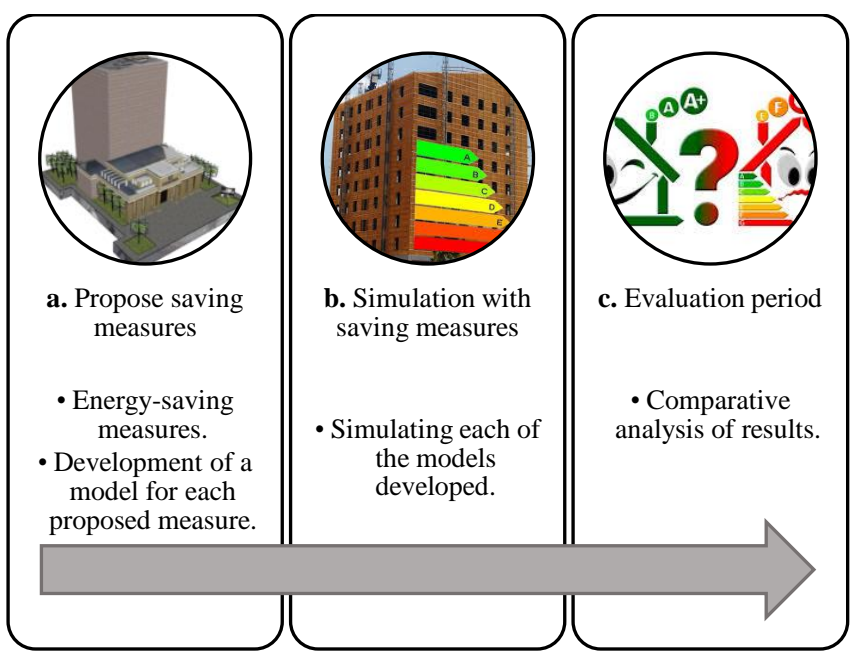

Fig. 5 Measures simulation and evaluation process.

The measures are established based on technical criteria and their effect on building consumption. They will be evaluated by comparing the simulation predicted data from each simulation performed whit the baseline results.

Several models have been developed from the baseline scheme to simulate changes introduced by some proposed energy savings measures. The measures proposed are focused on the optimization of chilled water plant -the main component of the HVAC system.

Two saving measures are suggested to reduce the energy consumption of the HVAC system; each one with two alternative forms of implementation that will be simulated. Developed models need to be analyzed independently to know the effects of each proposed measures, for this, it the designation given in Table III is introduced.

TABLE III

DESIGNATION FOR MODELS

\begin{tabular}{|c|l|}
\hline Models & \multicolumn{1}{c|}{$\begin{array}{c}\text { Alternatives considered in the models } \\
\text { Measure 1: Reduction of the pressure head in the chiller of the } \\
\text { chilled-water plant. }\end{array}$} \\
\hline M1A1 & Decrease the inlet condenser water temperature. \\
\hline M1A2 & Increase in outlet chilled-water temperature. \\
\hline \multicolumn{2}{|c|}{ Measure 2: Implementation of variable frequency drives. } \\
\hline M2A1 & $\begin{array}{l}\text { Implement variable frequency drives in the inlet-water } \\
\text { pumps to the evaporator. }\end{array}$ \\
\hline M2A2 & $\begin{array}{l}\text { Replace the current chiller with a new chiller possessing } \\
\text { variable frequency drives. }\end{array}$ \\
\hline
\end{tabular}

Reducing the lift (pressure head) is proposed to decrease the compression power. These would allow improving the chiller performance and therefore, reduce energy consumption in chilled-water plant [17]. The adjustment variables in the model are the entering-condenser-water temperature (ECWT) and the leaving chilled-water temperature (LCHWT), considering that the condenser-water flow is constant.

The following mechanical components of HVAC system are considered for the implementation of variable frequency drives (VFD): the inlet-water pumps to the evaporator and the compressor of the chiller.

It should be mentioned that in the first case an adaptation of the initial system pumps is proposed; while in the second case, a replacement of the conventional chiller $(450 \mathrm{TON})$ for a VFD chiller is proposed [18].

\section{RESULTS}

The results of the first part of this study consist of the determination of a calibrated baseline model. Among the defined features in the development of the model are: the environmental conditions, the geometry of the building, materials and constructions of the envelope, usage and occupancy profiles, types of spaces, thermal zones, cooling loads and installed systems. Figure 6 presents a threedimensional view of the building that was modeled using the OpenStudio plug-in from the SketchUp workspace.

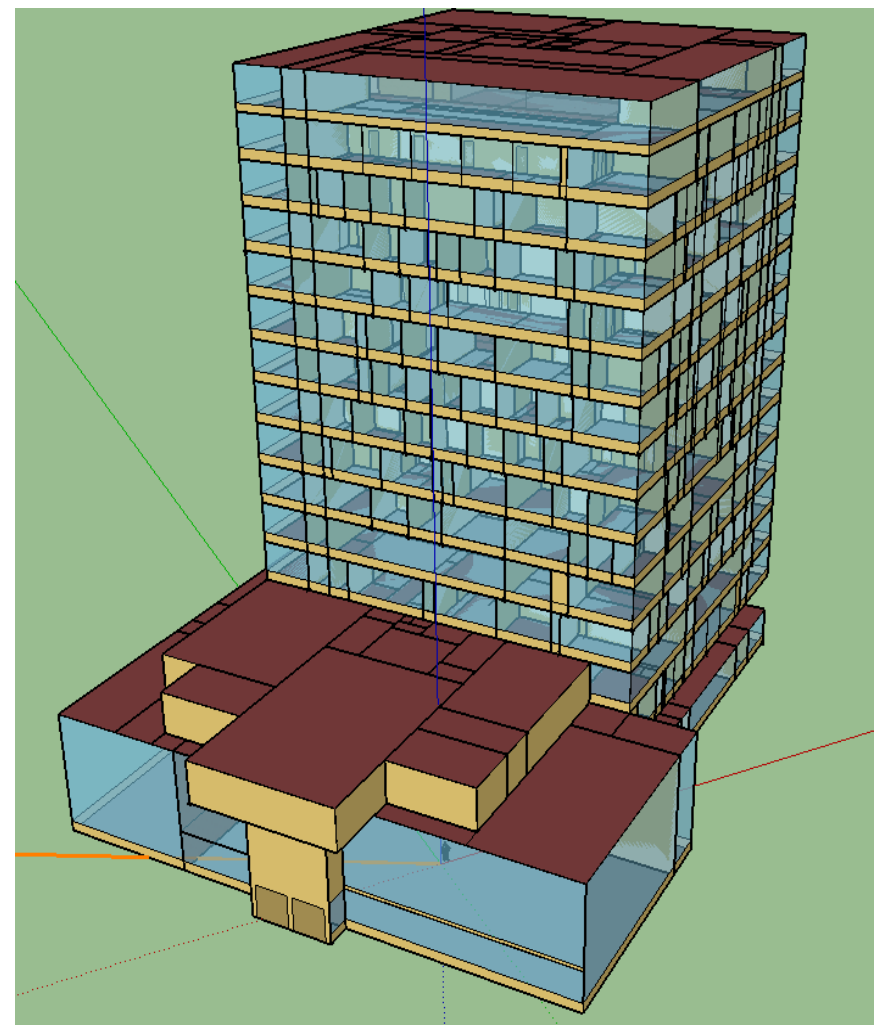

Fig. 6 Three-dimensional view of the modeled building.

The energy baseline consists of the results of the annual simulation. Simulated monthly consumptions are validated using calibration indices, for that the monthly consumption during a yearly period is considered. Table IV presents both simulated and real demand, values are in $\mathrm{kW}-\mathrm{h}$. 
TABLE IV

SIMULATED AND REAL CONSUMPTIONS

\begin{tabular}{|c|c|c|}
\hline Months & $\begin{array}{c}\text { Simulated } \\
\text { Consumption }\end{array}$ & $\begin{array}{c}\text { Average } \\
\text { Consumption }\end{array}$ \\
\hline January & $309.769,90$ & $310.100,00$ \\
\hline February & $298.415,40$ & $308.700,00$ \\
\hline March & $337.101,90$ & $342.300,00$ \\
\hline April & $311.206,20$ & $329.000,00$ \\
\hline May & $311.656,70$ & $296.100,00$ \\
\hline June & $323.503,60$ & $328.300,00$ \\
\hline July & $297.092,60$ & $289.100,00$ \\
\hline August & $336.073,90$ & $312.900,00$ \\
\hline September & $321.160,90$ & $314.370,00$ \\
\hline October & $308.040,10$ & $296.800,00$ \\
\hline November & $323.539,30$ & $317.100,00$ \\
\hline December & $310.913,80$ & $289.900,00$ \\
\hline
\end{tabular}

The indices "CVRMSE" and "NMBE" are calculated using the utility bills and simulated consumptions according to expressions (2) and (3). Table V presents the best results obtained during the iterative simulation process. In both cases the values obtained are within the acceptable range, so it can ensure that the model is calibrated, and their energy consumption could be used as the energy baseline.

TABLE V

CALCULATEd VALUES FOR SimUlation INDiCES

\begin{tabular}{|l|c|c|}
\hline \multicolumn{1}{|c|}{ Index } & $\begin{array}{c}\text { Tolerance } \\
{[\%]}\end{array}$ & $\begin{array}{c}\text { Simulated Value } \\
{[\%]}\end{array}$ \\
\hline $\mathrm{CVRMSE}_{\text {(month) }}$ & \pm 5 & 3,77 \\
\hline $\mathrm{NMBE}_{(\text {month) }}$ & \pm 15 & $-1,46$ \\
\hline
\end{tabular}

Figure 7 shows a graphical comparison between simulated consumption and the average real consumption. It is possible to observe that the month that presents the lower difference between real and simulated consumption is January $(0,11 \%)$, while the months with more differences are August $(7,41 \%)$ and December $(7,25 \%)$. Also, July is the month with the lower consumption value in both cases.

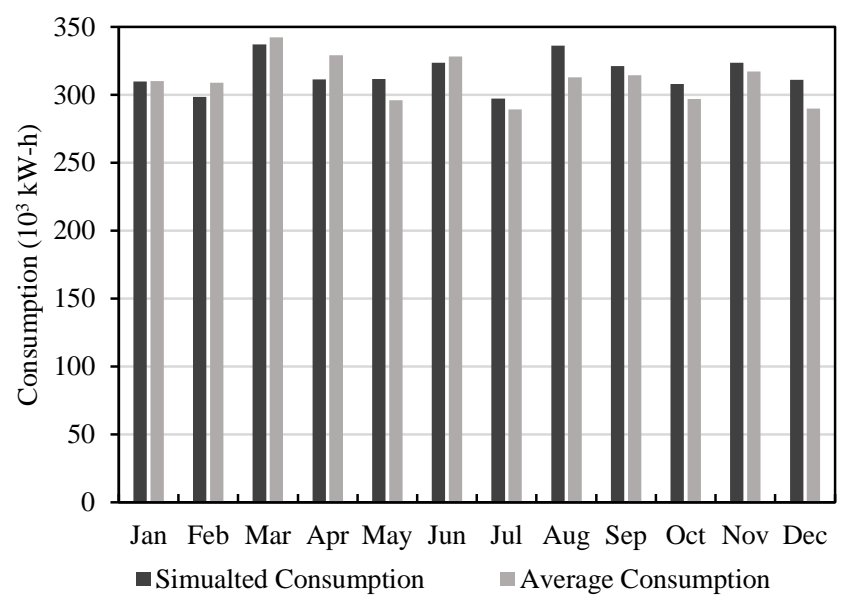

Fig. 7 Graphical comparison of simulation vs real consumption.
Figure 8 shows a comparison between the baseline energy consumption and the monthly simulated consumption for the M1A1 model; also the end uses of energy in each month can be observed. Although there are no significant reductions in electric consumption for the cooling demand, it is noticeable that the reduction is very regular in all months except August where the decrease is slightly higher.

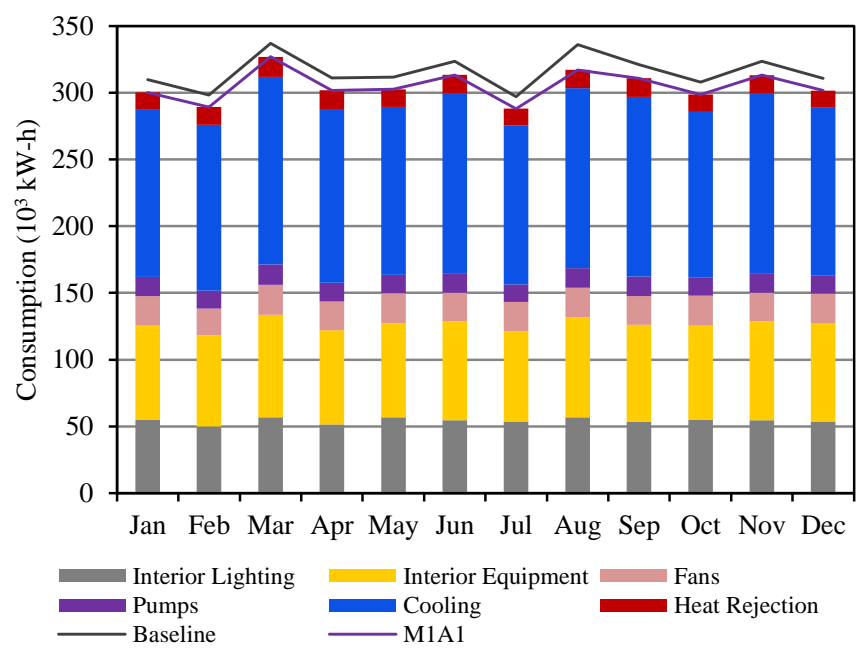

Fig. 8 Monthly simulation results for M1A1 model.

In Figure 9 the end uses of energy in each month for the M1A2 model can be observed; also a comparison between monthly energy consumptions of baseline and simulated model is shown. It is noted that exist a considerable reduction in energy consumption for cooling demand in the case M1A1, especially in the months from June to December; the month of August is the one with the largest decrease. During the months from January to May consumption reductions are negligible; March is the month reporting the smallest decrease.

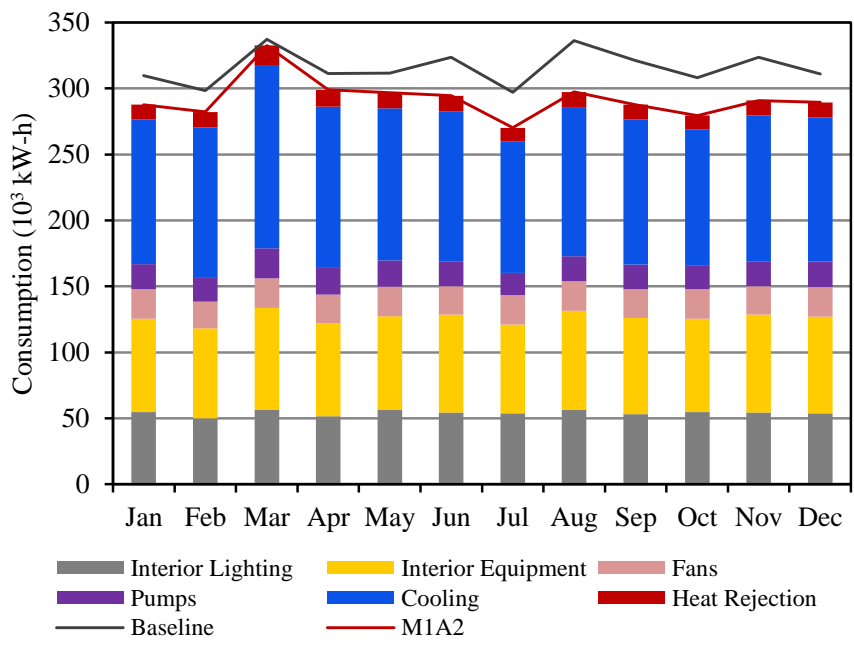

Fig. 9 Monthly simulation results for M1A2 model.

$14^{\text {th }}$ LACCEI International Multi-Conference for Engineering, Education, and Technology: "Engineering Innovations for Global Sustainability", 20-22 July 2016, San José, Costa Rica. 
In the case of the M2A1 model, the simulated monthly consumption is not reduced significantly compared to the baseline in any of the months, as observed in Figure 10. It is also appreciated that the proportion of energy reduction is regular throughout the year, except in the month of August where energy decreases slightly larger. March is the month with the largest energy consumption, on the other hand, the lower power consumption occurs in July.

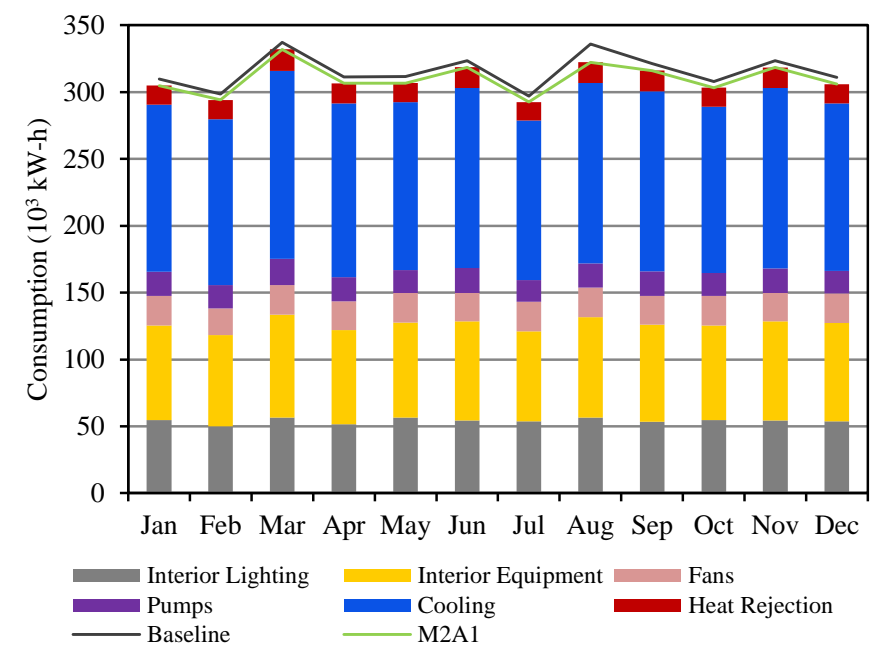

Fig. 10 Monthly simulation results for M2A1 model.

Figure 11 shows the end uses and the total consumption obtained from the simulation of the model M2A2 during an annual period. A drastic reduction in monthly consumption for cooling is observed for most of the year except in the months from February to April. The month with the highest registered consumption was March, while; the month with the lowest consumption was July and the month with the largest decrease in consumption was August. The months of March and April do not present reduction in electric consumption.

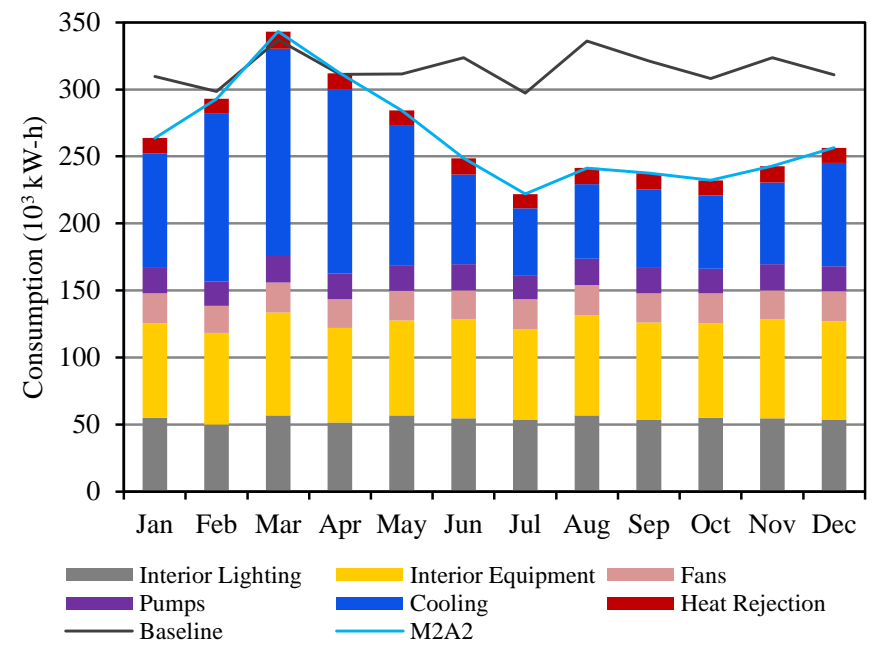

Fig. 11 Monthly simulation results for M2A2 model.

\section{DISCUSSION}

In all simulated models, consumption reduction with respect to the baseline was obtained. The first proposed saving measure M1A1 model shows a reduction of $3.28 \%$ of annual consumption; while for the alternative proposed in M1A2 model, the reduction was $7.42 \%$. On the measure of the implementation of variable frequency drives in HVAC equipment, in the alternative M2A1 the reduction was $1.76 \%$, while; for the alternative in M2A2 model a saving of 16,15\% was obtained. Figure 12 shows the annual electricity consumption of the simulated models.

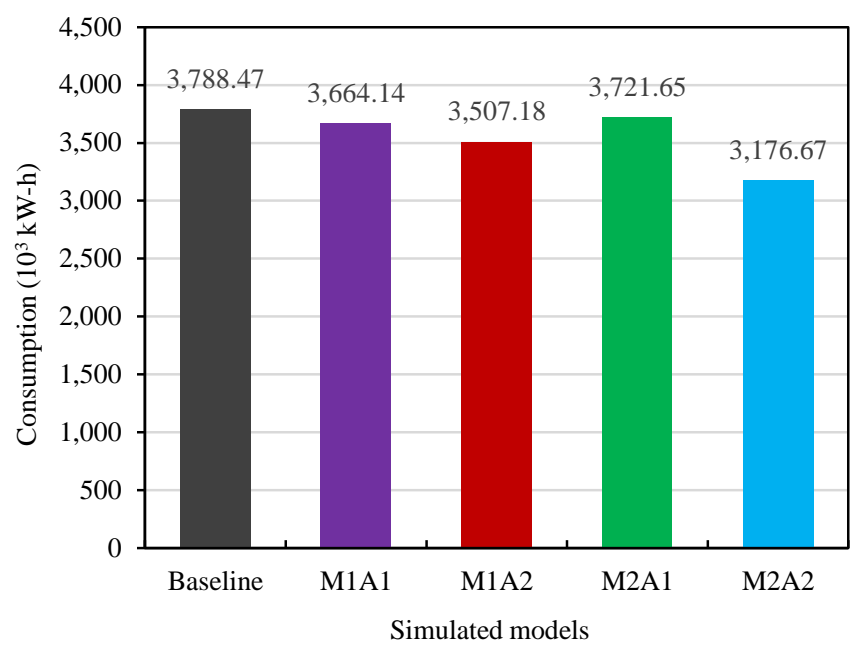

Fig. 12 Annual consumptions comparison for simulated models.

The alternatives simulated on the M1A1 and M2A1 models produced little significant savings. The decrease in the condenser inlet temperature is limited by the environmental conditions of the city of Guayaquil. In the second model, the application of variable frequency drives to the pumps results in savings $19.85 \%$ for pumping. However; in total consumption this category represents only $7.06 \%$.

TABLE VI

SUMMARY OF THE SAVINGS ACHIEVED

\begin{tabular}{|c|l|c|}
\hline Model & \multicolumn{1}{|c|}{ Saving measure } & Percent \\
\hline M1A1 & $\begin{array}{l}\text { Decrease in the entering-condenser-water } \\
\text { temperature. }\end{array}$ & $\mathbf{3 . 2 8 \%}$ \\
\hline M1A2 & $\begin{array}{l}\text { Increase in the leaving chilled-water } \\
\text { temperature. }\end{array}$ & $\mathbf{7 . 4 2 \%}$ \\
\hline M2A1 & $\begin{array}{l}\text { Implement variable frequency drives in the } \\
\text { pumps for water of entry to the evaporator. }\end{array}$ & $\mathbf{1 . 7 6 \%}$ \\
\hline M2A2 & $\begin{array}{l}\text { Replace the current chiller with a new chiller } \\
\text { possessing variable frequency drives. }\end{array}$ & $\mathbf{1 6 . 1 5 \%}$ \\
\hline
\end{tabular}

In the M1 A2 and M2A2 models, the savings achieved are significantly higher than in previous cases. In the simulation of M1A2, the results show a clear impact of this measure on

$14^{\text {th }}$ LACCEI International Multi-Conference for Engineering, Education, and Technology: "Engineering Innovations for 
cooling and pumping consumption with reductions of $13.18 \%$ and $14 \%$ respectively.

It is possible to achieve a greater reduction in energy consumption by the simultaneous implementation of the saving measures previously presented. For this reason; it is proposed to simulate additional models containing combinations of the alternatives.

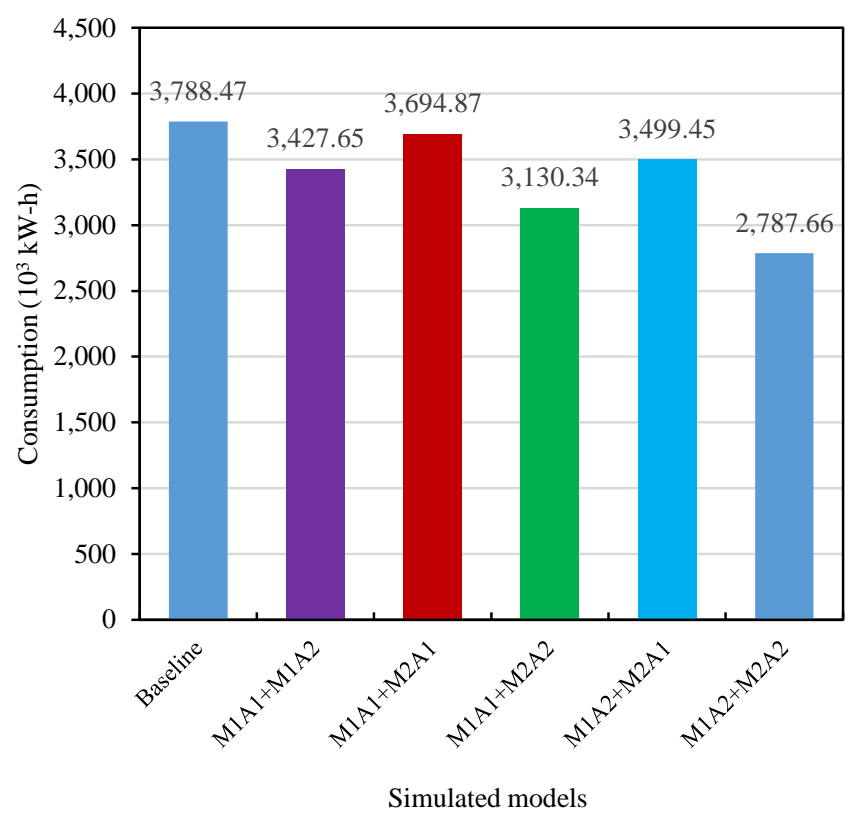

Fig. 13 Annual consumption combining alternatives.

Figure 13 shows the simulated consumption obtained for each combination. It is observed that the models that include replacing the current chiller recorded the lowest consumptions, however; the model that combines the M1A2 and M2A2 alternatives reached savings of $26.42 \%$.

\section{CONCLUSIONS}

The application of technical approaches for improving the performance of HVAC equipment can achieve significant energy savings; being increased the entering water temperature to evaporator the alternative that allows a further reduction in consumption $(7.42 \%)$ without replacing the equipment. For the approach of replacing conventional chiller, one with variable frequency drive was obtained $16.15 \%$ reduction in consumption.

The application of variable-frequency drive in HVAC system is a measure that proved capable of generating significant savings in energy consumption. However; implementing this measure involves modifying or replacing equipment currently in the system in operation. For that reason; it is necessary to ensure that major savings in total consumption will be obtained to justify its implementation, such is the case of the second alternative where a reduction of $16.15 \%$ was obtained.
This study has estimated that it is possible to obtain up to $26.42 \%$ savings for the building "Zonal Government of Guayaquil." Similar studies could evaluate the implemented measures and identify opportunities for greater impact on energy consumption and achieve better energy performance in public buildings.

The combination of energy-saving measures proved to be effective in reducing power consumption. In this work, adjustment and modification of HVAC equipment were analyzed, however; it would be interesting to conduct an analysis to include other measures such as envelope changes and lighting control.

\section{ACKNOWLEDGMENT}

The authors would like to thank the administration of the building "Government Zone of Guayaquil" for the facilities provided for the development of this study.

\section{REFERENCES}

[1] Peralta J., López Á., Barriga A., \& Sosa I. (2013). Análisis estadístico de la información meteorológica para la explotación de energías renovables en el Ecuador. Conference Paper, (2), 9-9.

[2] Instituto Oceanográfico de la Armada. (2005). Derrotero de la costa continental e insular del ecuador (4). Armada del Ecuador.

[3] Instituto Nacional de Meteorología e Hidrología (2013, Quito-Ecuador). Anuario Meteorológico 2011, p. 104.

[4] ASHRAE, Thermal environmental conditions for human occupancy. ANSI/ASHRAE Standard 55-2010., ASHRAE, Atlanta, Ga, 2010.

[5] Agencia Chilena de Eficiencia Energética: razones de la adopción del modelo público-privado y sus implicancias. Análisis crítico del marco institucional. Taller de memoria: "Instrumentos para la elaboración de una política energética sustentable.” No. 11100288, 2010-2012.

[6] Ministerio de Electricidad y Energías Renovables (MEER), Plan de Eficiencia Energética en el Ecuador. Noviembre, 2010.

[7] ASHRAE, Thermal environmental conditions for human occupancy. ANSI/ASHRAE Standard 55-2010., ASHRAE, Atlanta, Ga, 2010.

[8] 2010, "ASHRAE Standard 90.1-2010, Energy standard for buildings except low-rise residential buildings," American Society of Heating, Refrigeration, and Air-Conditioning Engineers, Inc., 1791 Tullie Circle, NE, Atlanta, GA30329, USA.

[9] A. Alvear, P. Peña Toro \& J. Labus, (2013). Green Building: Ecuadorian Case. Revista Tecnológica ESPOL - RTE, Vol. 26, N. 2, 28-43.

[10]J. Macías, G. Soriano, H. Sánchez \& Y. Canchingre. (2015). Assessment of solar reflectance of roofing assemblies of dwellings in Guayaquil, Ecuador. WIT Transaction on Ecology and The Environment, Vol. 195, 307-315. ISSN 1743-3541 (on-line), doi: 10.2495/ESUS150261.

[11]C. Naranjo, G. Gaona, J Lopez and J. Labus, (2014). Performance analysis with future predictions of different solar cooling systems in Guayaquil, Ecuador. ASME Conference Proceedings.

[12]Krarti, M. (2000). Energy audit of building systems: An engineering approach. Boca Raton, FL: CRC Press.

[13]American Society of Heating, Refrigerating and Air-Conditioning Engineers. (2007). 2007 ASHRAE handbook: Fundamentals. Atlanta, GA: ASHRAE.

[14]OpenStudio user documentation: Installation and Introductory Tutorial, National Renewable Energy Laboratory (NREL), Retrieved from: http://nrel.github.io/OpenStudio-userdocumentation/getting_started/getting_started/.

[15]Drury B. Crawley, , Linda K. Lawrie, Frederick C. Winkelmann, W.F. Buhl, Y. Joe Huang, Curtis O. Pedersen, Richard K. Strand, Richard J. Liesen, Daniel E. Fisher, Michael J. Witte, Jason Glazer, EnergyPlus: creating a new-generation building energy simulation program 
[16]ASHRAE Guideline 14 (2002), Measurement of energy and demand savings, American Society of Heating, Refrigerating and Air-Conditioning Engineers.

[17]Mick Schwedler, P.E., and Beth Bakkum, November 2009, "Upgrading Chilled-Water Systems", ASHRAE Journal, 17p.

[18]Thomas Hartman, P.E., September 2001, "All-Variable Speed Centrifugal Chiller Plants", ASHRAE Journal: Centrifugal Chillers, 43, 44p.

$14^{\text {th }}$ LACCEI International Multi-Conference for Engineering, Education, and Technology: "Engineering Innovations for Global Sustainability”, 20-22 July 2016, San José, Costa Rica. 